\author{
Antoine Roch \\ Laurent Papazian
}

\section{Rescue therapy for refractory ARDS should be offered early: we are not sure}

Received: 13 February 2015

Accepted: 17 February 2015

Published online: 20 March 2015

(C) Springer-Verlag Berlin Heidelberg and ESICM 2015

For contrasting viewpoints, please go to

doi:10.1007/s00134-015-3704-6 and

doi:10.1007/s00134-015-3721-5.

\section{A. Roch}

Assistance Publique-Hôpitaux de Marseille, Hôpital Nord, Service d'Accueil des Urgence, Marseille, France

\section{Papazian (乘)}

Assistance Publique-Hôpitaux de Marseille, Hôpital Nord, Réanimation des Détresses Respiratoires et Infections Sévères, 13015 Marseille, France

e-mail: laurent.papazian@ap-hm.fr

Tel.: +33491965835

A. Roch · L. Papazian

Aix-Marseille Université, Faculté de Médecine, URMITE UMR CNRS 7278, Marseille, France

Clinical vignette A previously healthy 51-year-old woman was admitted to the intensive care unit (ICU) with severe community-acquired pneumonia. She required intubation and mechanical ventilation $6 \mathrm{~h}$ after admission. Her respiratory status declined continuously over the next few hours, and her $\mathrm{PaO}_{2} / \mathrm{FiO}_{2}$ ratio was 65 with a positive end-expiratory pressure (PEEP) at 8-12 h after admission (plateau pressure was 28). She was hemodynamically stable and had normal renal function.

Extracorporeal membrane oxygenation (ECMO) is an old technique which is highly dependent on development of new technologies. The concomitant publication of the CESAR trial [1] and the occurrence of the H1N1
2009-2010 pandemic [2] raised numerous questions about the place of ECMO in the symptomatic treatment of acute respiratory distress syndrome (ARDS). Schematically, ECMO should reach two objectives: to maintain adequate gas exchange when there is dramatic hypoxemia and/or profound acidosis with high degree of hypercapnia, and to preserve the lung from potential volu-, baro-, and biotrauma associated with mechanical ventilation. We should therefore consider that, for the first objective, we can wait to a certain degree to start ECMO, while for the second objective we have to be more proactive regarding ECMO. This is the challenge in 2015 while awaiting future significant technological improvements or new scientific proof of the efficacy of ECMO regarding ARDS outcome.

When considering this clinical vignette, this patient is a potential good candidate for ECMO, presenting single organ failure (the lung) with a short delay since intubation $[3,4]$. At this point and regarding PEEP and plateau pressure level, we can assume that there is potential for oxygenation improvement by adjusting ventilator parameters. As this ARDS is severe, we should first paralyze this patient. After a bolus dose of a neuromuscular blocker, we have to institute continuous infusion of this drug. Immediately after, we must reassess ventilator parameters. We can increase PEEP and observe the concomitant rise in plateau pressure (if using a volumecontrolled mode). The plateau pressure limit is highly dependent on the patient. If she is obese, plateau pressure of $32 \mathrm{cmH}_{2} \mathrm{O}$ would be within acceptable limits; otherwise, $30 \mathrm{cmH}_{2} \mathrm{O}$ is acceptable. However, as the cause of ARDS is community-acquired pneumonia (CAP), the distribution of lung lesions is probably heterogeneous. There is therefore a substantial risk of inefficacy of high PEEP levels related to huge differences in regional compliances. This is the reason why prone position has to be used early after adjusting PEEP level. Since the studies done by Mancebo [5], the meta-analysis of Gattinoni [6], and the PROSEVA study by Guérin [7], we know that 
prone positioning can improve survival when applied early in the course of ARDS, when $\mathrm{PaO}_{2} / \mathrm{FiO}_{2}(\mathrm{P} / \mathrm{F})$ ratio is lower than 150. It is therefore difficult to not consider prone positioning before implementing ECMO. Moreover, use of prone positioning has been shown to significantly reduce the need for ECMO in severe ARDS patients [7]. Just before proning the patient, it is essential to evaluate right ventricular function. The presence of right ventricular dysfunction could justify introduction of inhaled nitric oxide. However, improvement of oxygenation by itself can decrease right ventricular afterload by limiting pulmonary vasoconstriction. After turning the patient prone, PEEP level should be reevaluated [8] as the modification of repartition of lung densities can alter PEEP response. However, if after a few hours of proning, there is persistent severe hypoxemia $(\mathrm{P} / \mathrm{F}<70-80$ for centers without ECMO and needing to call a mobile unit; $\mathrm{P} / \mathrm{F}<60-70$ for ECMO centers), ECMO should be started promptly. To date, the benefit/risk ratio of ECMO treatment needs further evaluation. Therefore, attention should first be paid in this patient to elimination of any contraindication to heparin, any risk factor for intracerebral bleeding or immunosuppression. In this latter case, the prognosis of patients treated with ECMO has been shown to be poor [3, 4]. ECMO should ideally be provided with femoral-jugular cannulation at a flow of at least $60 \%$ of the predicted cardiac output and a sweep gas flow to obtain a $\mathrm{PaCO}_{2}$ compatible with $\mathrm{pH}>7.25$. No consensus exists on ventilator settings under ECMO. However, one study suggested better prognosis in patients with lower plateau pressure at day 1 after ECMO initiation [2]. Therefore, plateau pressure of $22-25 \mathrm{cmH}_{2} \mathrm{O}$ should be considered as acceptable, with driving pressure of 8-15 $\mathrm{cmH}_{2} \mathrm{O}$ and resulting PEEP of $12-18 \mathrm{cmH}_{2} \mathrm{O}$ in order to rest the lung. As discussed above, as the cause of ARDS is CAP, the distribution of lung lesions is probably heterogeneous, and there is therefore substantial risk of inefficacy of high PEEP levels. However, the reduction of both tidal volume and driving pressure under ECMO may allow for higher PEEP levels than under conventional ventilation. Indeed, the risk of overdistension of anterior lung regions is reduced in this situation. Although the prognostic impact of prone positioning under ECMO has not been evaluated, it has been shown to further improve oxygenation [9]. While prone positioning could be insufficient in this patient to prevent ECMO requirement, it should probably be continued after initiating ECMO if performed by trained teams [9]. Criteria for prone positioning initiation and weaning in ECMO patients remain to be evaluated in future studies.

In some patients, ECMO should be considered urgently for immediate life-threatening condition. In such cases, the benefit/risk ratio is very probably in favor of ECMO although the cost/benefit ratio may be questionable. When regarding the present clinical vignette, it is likely that, in this 51-year-old, previously healthy patient, a $\mathrm{P} / \mathrm{F}$ ratio of $65 \mathrm{mmHg}$ is safe for a period of time sufficient to discuss the indication for ECMO with an experienced team, ideally located in a reference center and equipped with a mobile team. Indeed, ECMO treatment may be associated with better prognosis when initiated and managed by highly trained personnel [10]. The cutoff for P/F ratio and the duration of hypoxemia before ECMO initiation are still a matter of debate and are currently being explored in ongoing randomized controlled trials (RCTs).

In conclusion, ECMO may be indicated in this patient, but not at this stage, since prone positioning has not been performed, having been shown to reduce the need for ECMO in severe ARDS patients [7]. However, in this patient without contraindication and with single organ failure, use of venovenous ECMO should be considered without delay if the $\mathrm{P} / \mathrm{F}$ ratio decreases below $55-60 \mathrm{mmHg}$ for at least $3 \mathrm{~h}$, despite a protective ventilation strategy (including use of prone positioning). ECMO should be discussed if the $\mathrm{P} / \mathrm{F}$ ratio is below $80 \mathrm{mmHg}$ when $\mathrm{FiO}_{2}=1$ for more than $6 \mathrm{~h}$, despite a protective ventilation strategy (involving use of prone positioning) or in case of respiratory acidosis with $\mathrm{pH}<$ 7.20 for over $6 \mathrm{~h}$ despite a protective ventilation strategy [10].

Conflicts of interest A.R. and L.P. do not have any conflicts of interest to declare regarding this manuscript.

\section{References}

1. Peek GJ, Mugford M, Tiruvoipati R, Wilson A, Allen E, Thalanany MM et al (2009) Efficacy and economic assessment of conventional ventilatory support versus extracorporeal membrane oxygenation for severe adult respiratory failure (CESAR): a multicentre randomised controlled trial. Lancet 374(9698):1351-1363
2. Pham T, Combes A, Roze H, Chevret $\mathrm{S}$, Mercat A, Roch A et al (2013) Extracorporeal membrane oxygenation for pandemic influenza $\mathrm{A}(\mathrm{H} 1 \mathrm{~N} 1)$ induced acute respiratory distress syndrome: a cohort study and propensity-matched analysis. Am J Respir Crit Care Med 187(3):276-285
3. Roch A, Hraiech S, Masson E, Grisoli D, Forel JM, Boucekine M et al (2014) Outcome of acute respiratory distress syndrome patients treated with extracorporeal membrane oxygenation and brought to a referral center. Intensive Care Med 40(1):74-83 
4. Schmidt M, Zogheib E, Roze H, Repesse X, Lebreton G, Luyt CE et al (2013) The PRESERVE mortality risk score and analysis of long-term outcomes after extracorporeal membrane oxygenation for severe acute respiratory distress syndrome. Intensive Care Med 39(10):1704-1713

5. Mancebo J, Fernandez R, Blanch L, Rialp G, Gordo F, Ferrer M et al (2006) A multicenter trial of prolonged prone ventilation in severe acute respiratory distress syndrome. Am J Respir Crit Care Med 173(11):1233-1239

6. Gattinoni L, Carlesso E, Taccone P, Polli F, Guerin C, Mancebo J (2010) Prone positioning improves survival in severe ARDS: a pathophysiologic review and individual patient metaanalysis. Minerva Anestesiol 76(6):448-454
7. Guerin C, Reignier J, Richard JC, Beuret P, Gacouin A, Boulain T et al (2013) Prone positioning in severe acute respiratory distress syndrome. New Engl J Med 368(23):2159-2168

8. Gainnier M, Michelet P, Thirion X, Arnal JM, Sainty JM, Papazian L (2003) Prone position and positive endexpiratory pressure in acute respiratory distress syndrome. Crit Care Med 31(12):2719-2726

9. Guervilly C, Hraiech S, Gariboldi V, Xeridat F, Dizier S, Toesca R et al (2014) Prone positioning during venovenous extracorporeal membrane oxygenation for severe acute respiratory distress syndrome in adults. Minerva Anestesiol 80(3):307-313
10. Richard C, Argaud L, Blet A, Boulain T, Contentin L, Dechartres A et al (2014) Extracorporeal life support for patients with acute respiratory distress syndrome: report of a consensus conference. Ann Intensive Care 4:15 